\title{
CHARACTERIZATION OF EVAPORATED SOLID-PHASE CRYSTALLIZED SILICON THIN-FILM SOLAR CELLS ON GLASS
}

\author{
Fude Liu, ${ }^{1}$ M.J. Romero, ${ }^{1}$ K.M. Jones, ${ }^{1}$ O. Kunz, ${ }^{2}$ J. Wong, ${ }^{2}$ R.C. Reedy, ${ }^{1}$ A.G. Aberle, ${ }^{2 *}$ and M.M. Al-Jassim ${ }^{1}$ \\ ${ }^{1}$ National Center for Photovoltaics, National Renewable Energy Laboratory, Golden, CO 80401, USA \\ ${ }^{2}$ ARC Photovoltaics Centre of Excellence, The University of New South Wales, Sydney NSW 2052, Australia \\ * Now with: Solar Energy Research Institute of Singapore, National University of Singapore, Singapore 117576
}

\begin{abstract}
Following our previous study on the material-quality limiting factors of evaporated solid-phase crystallized (SPC) poly-Si thin films fabricated on planar glass for photovoltaic applications, we extend our study to investigate the impurity levels, optical properties, transport properties, and device performance of so-called "EVA" (EVAporated $\mathrm{Si}$ ) solar cells. These potentially costeffective cells are systematically characterized with electron microscopy-based techniques, external quantum efficiency, and standard current-voltage measurements. We conclude that $5 \%$ efficient cells are now attainable, and much room remains for further improving device performance. We are confident that 10\%-efficient EVA solar cells will be realized in the future, with proper metallization schemes, good light trapping, and improved poly-Si film quality.
\end{abstract}

\section{INTRODUCTION}

Much interest has been shown in silicon thin-film solar cells because of their potential for low cost and other benefits such as non-toxicity and the essentially unlimited supply of basic materials [1, 2]. Among silicon thin-film technologies, polycrystalline silicon (poly-Si) (grain size: 1 $\mu \mathrm{m}$ to $1 \mathrm{~mm}$ ) is a promising emerging technology. Poly-Si thin films have better transport properties and are not subject to light-induced degradation effects [1, 3], compared to hydrogenated amorphous silicon (a-Si:H) and microcrystalline silicon ( $\mu \mathrm{c}-\mathrm{Si}: \mathrm{H}$ ) films. Rapid progress is being made and some promising results have been achieved in this field in the last several years. In particular, solid-phase crystallization (SPC) of a-Si has been the most successful and widely studied poly-Si film formation technique without using a seed layer [4-7]. The a-Si films are usually deposited by plasma-enhanced chemical vapor deposition (PECVD), hot-wire CVD (HWCVD), sputtering, or e-beam evaporation, and they are then solid-phase crystallized at a temperature in the $550-700^{\circ} \mathrm{C}$ range during a time ranging from a few hours to several tens of hours.

In this work, we focus on EVA solar cells on glass, where EVA stands for "solid-phase crystallization of EVAporated Si." These solar cells have been developed at the University of New South Wales (UNSW) and represent a promising approach for lowering the cost of photovoltaic
(PV) solar electricity [8]. The combination of e-beam evaporation at low temperature in a non-ultra-high vacuum (non-UHV) environment and atmospheric-pressure SPC in a tube furnace provides a simple, inexpensive way to form poly-Si thin-film solar cell materials and is especially applicable to low-temperature glass substrates [9]. It offers specific advantages over other approaches, such as very high Si deposition rate, excellent Si source material usage, avoidance of toxic gases, and simple sample preparation conditions [9]. To date, the efficiency of EVA solar cells is not yet as high as that of amorphous or microcrystalline Si cells. However, great progress has been made in EVA solar cells and the efficiency now exceeds $4.2 \%$ [8, 10]. In our previous work [11], we investigated the material quality of EVA poly-Si films. It was found that the grains in these poly-Si thin films are randomly oriented, with an average grain size of $\sim 2.1 \mu \mathrm{m}$; the grains are defective and substantial densities of impurities are incorporated; the optical activity of the Si film is dominated by deep band tail states. In the present work, we investigate the impurity levels, optical properties, transport properties, and device performance of EVA solar cells.

\section{EXPERIMENTAL}

The solar cell structure (glass $/ \mathrm{SiN} / \mathrm{p}^{+} / \mathrm{n} / \mathrm{n}^{+}$) was fabricated on a planar glass substrate (Borofloat33 from Schott AG) covered by a $\sim 70-\mathrm{nm}$ SiN antireflection/barrier layer deposited by PECVD. An approximately $2 \mu \mathrm{m}$ thick a-Si layer was then e-beam evaporated and in-situ doped at low substrate temperature $\left(200-240^{\circ} \mathrm{C}\right)$ in a non-UHV environment at a deposition pressure of $\sim 10^{-7}$ Torr (no hydrogen added to the process). The thickness and doping density of the different layers are as follows: 100 $\mathrm{nm} \mathrm{p}^{+}$-type emitter $\left(\sim 1 \times 10^{19} \mathrm{~cm}^{-3}\right.$, boron $), 1.8 \mu \mathrm{m}$ n-type

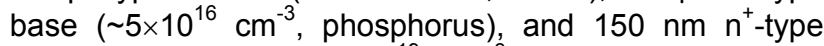
back-surface field $\left(\sim 5 \times 10^{19} \mathrm{~cm}^{-3}\right.$, phosphorus $)$. Upon deposition, the a-Si was crystallized by SPC in a tube furnace $\left(\mathrm{N}_{2}, 600^{\circ} \mathrm{C}, 24 \mathrm{~h}\right)$. A rapid thermal annealing (RTA) was carried out at $900^{\circ} \mathrm{C}$ for $\sim 4$ min after SPC. Then, the samples received a 15-20-min hydrogen plasma treatment at $600-650^{\circ} \mathrm{C}$ for defect passivation, using a remote-plasma tool. Finally, the cells were metallized [10,12]. The EVA solar cells were fabricated in the PV laboratories at the UNSW. Further details on cell preparation can be found elsewhere $[5,9]$.

A number of samples were systematically characterized with several techniques. Impurity levels and dopant concentrations in the poly-Si film were analyzed by 
depth profiling with a secondary-ion mass spectrometry (SIMS) instrument (Cameca IMS-5F). Cathodoluminescence (CL) spectrum mapping was acquired on a JEOL 5800 scanning electron microscope (SEM) to study the optical activity of the Si film. The measurement of the effective minority diffusion lengths was also carried out on this microscope to study the carrier transport in the poly-Si films. Cross-sectional transmission electron microscopy (TEM) specimens were prepared using a focused-ion-beam (FIB) workstation (FEl-Nova 200 Dual Beam). These specimens were then investigated by a field-emission TEM microscope (FEI-F20) at $200 \mathrm{kV}$ with Z-contrast imaging. Electrical characterization methods include external quantum efficiency (EQE) and standard current density-voltage (JV) measurements of EVA solar cells.

\section{RESULTS AND DISCUSSION}
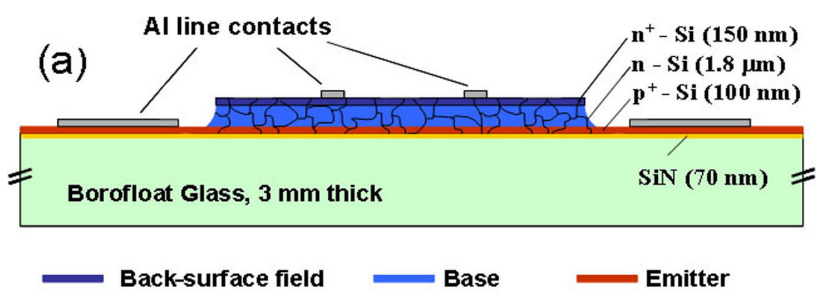

(b)

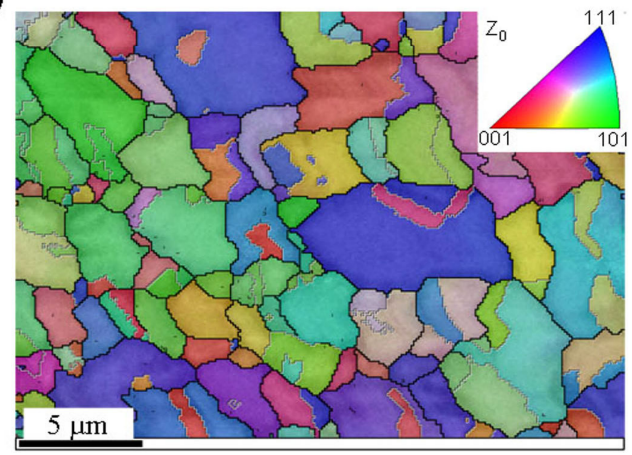

Fig. 1. (a) Schematic of the solar cell structure in superstrate configuration. (b) Plan-view EBSD map color-coded with the IPF coloring in the sample normal direction $Z_{0}$. The grain boundaries are highlighted with black lines and $\Sigma 3$ twins are highlighted with white lines. The inset is the color-coding legend.

Figure 1(a) shows schematically the solar cell structure in a superstrate configuration. Also shown is a typical plan-view electron backscatter diffraction (EBSD) map on the Si film surfaces not covered by Al contacts (Fig. 1(b)). The EBSD map is color-coded with the inverse pole figure (IPF) coloring in the sample normal direction $Z_{0}$, where the grain boundaries are highlighted with black lines and $\Sigma 3$ twins are highlighted with white lines. From this map, the average grain size is $\sim 2.1 \mu \mathrm{m}$, with a standard deviation of $\sim 1.3 \mu \mathrm{m}$, and silicon grains are oriented randomly, in general. There are also high intragrain defect densities in the Si films, as confirmed by our previous study [11]. More details on the grain-size distribution, grain orientation, and structural defects in the SPC poly-Si film have been reported elsewhere [11].
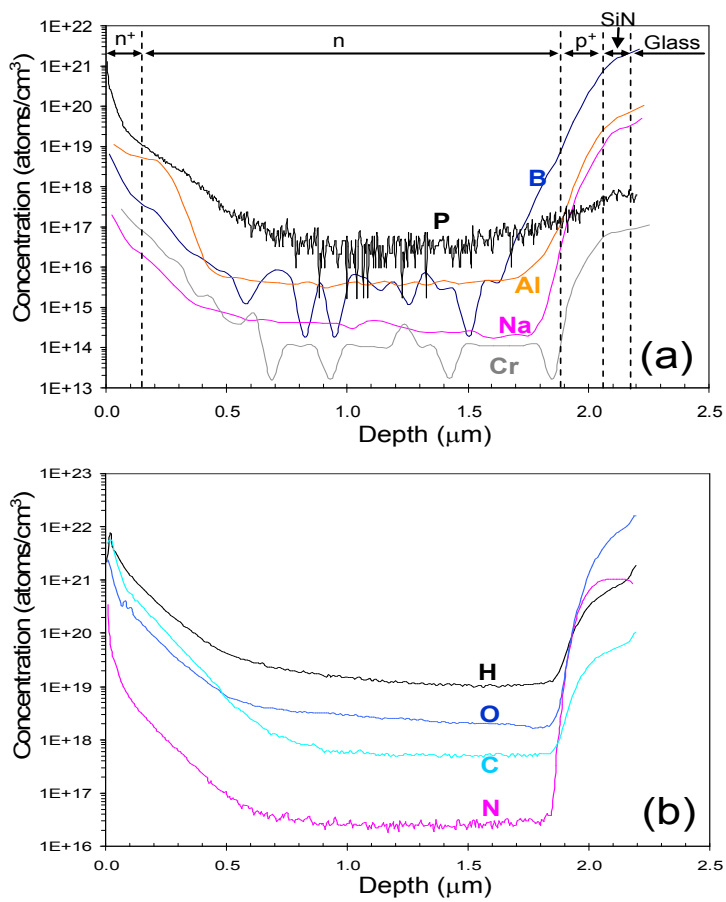

Fig. 2. (a) SIMS depth profiles of $\mathrm{N}, \mathrm{B}, \mathrm{Al}, \mathrm{Na}$, and $\mathrm{Cr}$. The dashed lines indicate roughly the locations of different layers as labeled in the figure. (b) SIMS depth profiles of $\mathrm{H}, \mathrm{O}, \mathrm{C}$, and $\mathrm{P}$.

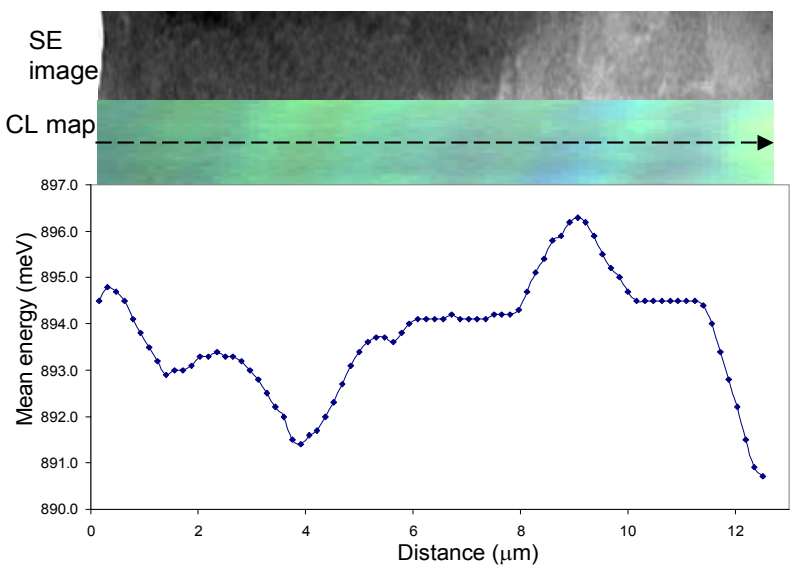

Fig. 3. CL mapping results. The secondary-electron (SE) image and its corresponding CL map acquired from the same area are shown on the top part. The arrow represents the energy line scan, which is shown in the lower part. The energy line scan corresponds to the mean energy of each CL spectrum acquired from each pixel on the arrow. 


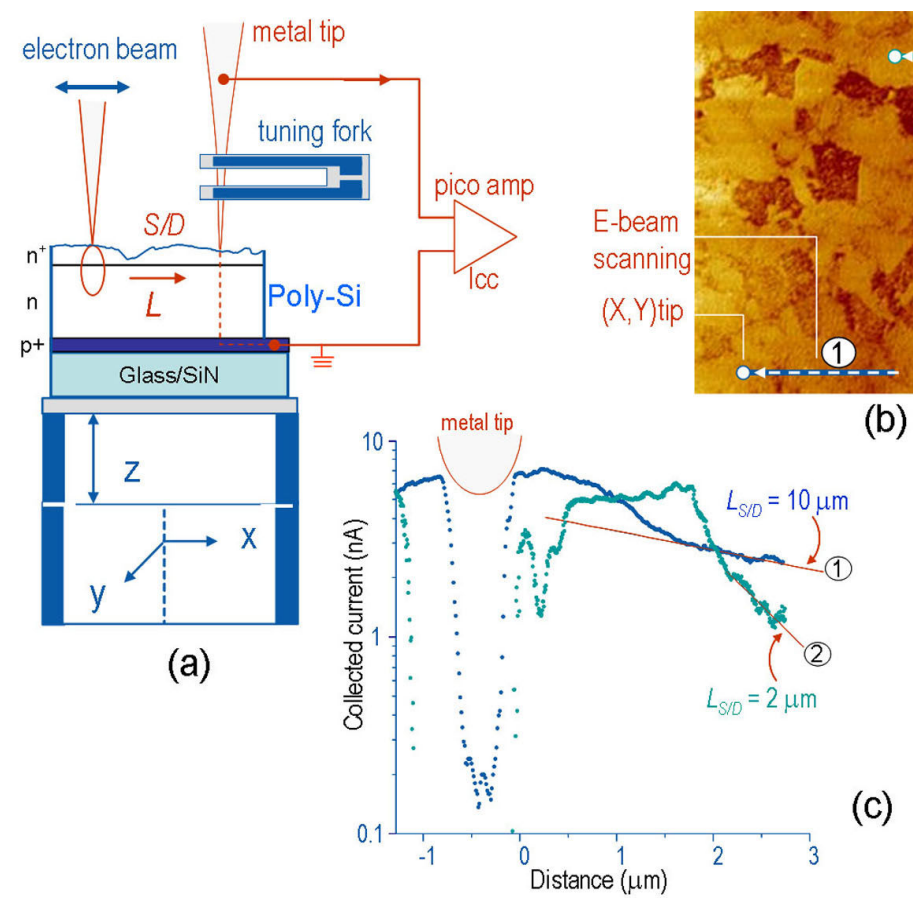

Fig. 4. (a) Schematic of the AFM-EBIC measurements. (b) AFM image of the poly-Si film. Also shown are the metal-tip positions and electron-beam scanning paths at two regions. (c) EBIC line-scan results. From the slopes of the plots, the effective diffusion lengths of the minority carriers can be derived.

Besides the structural defects mentioned above, impurities also play an important role in limiting device performance. In our previous study [11], we found that the oxygen impurity density is high in the poly-Si films, as indicated by the energy-dispersive X-ray spectroscopy (EDX) results. Here, we carried out a more detailed study of the impurity and dopant densities with SIMS, because of its much higher detection sensitivity compared to EDX. The SIMS depth profiles of impurities and dopants are shown in Fig. 2 to determine elemental distributions. The dopant densities are basically in the normal ranges as mentioned in the experimental part, although dopants smear out at the p-n junction, which is detrimental to device performance. The incorporation levels of $\mathrm{O}, \mathrm{C}$, and $\mathrm{N}$ in the poly-Si film are high-especially $\mathrm{O}$, with a density of $10^{18} \sim 10^{19} \mathrm{~cm}^{-3}$. However, this $\mathrm{O}$ level is not necessarily a problem because it is only slightly higher than in electronic-grade Czochralski (CZ) Si wafers where the $\mathrm{O}$ level is in the order of $10^{18} \mathrm{~cm}^{-3}$. In contrast, the incorporation levels of metals $(\mathrm{Na}$ and $\mathrm{Cr}$ ) are relatively low, except for $\mathrm{Al}$, with a density of $\sim 5 \times 10^{15} \mathrm{~cm}^{-3}$. The high level of $\mathrm{Al}$ incorporation is possibly due to residual $\mathrm{Al}$ from the metallization process [12]. The $\mathrm{H}$ density is in the range of $1 \times 10^{19} \sim 4 \times 10^{19} \mathrm{~cm}^{-3}$. Similar results on the $O$ and $\mathrm{H}$ levels in SPC poly-Si films have been reported in the literature [7, 13]. The high level of impurity incorporation could be due to impurities in the Si source material, the non-UHV conditions of the e-beam evaporation process, and/or the long SPC anneal in an $\mathrm{N}_{2}$ ambient. However, similar oxygen levels are also reported in the literature and seem to have little impact on the resulting poly-Si thin-film solar cell performance [13].

To study the optical activity of the Si film, we carried out $\mathrm{CL}$ spectrum measurements. A typical $\mathrm{CL}$ map is shown in Fig. 3. The secondary-electron (SE) image is shown on the top part, with its corresponding $C L$ map acquired from the same area. The arrow represents the energy line scan, which is shown in the lower part. The energy line scan corresponds to the mean energy of each CL spectrum acquired from each pixel on the arrow. In our previous study [11], we observed that an uncorrected spectrum is broad and red-shifted, with a peak energy of $\sim 0.87 \mathrm{eV}$ (the cut-off energy of the spectrum detector is $\sim 0.8 \mathrm{eV}$ ). From the line-scan plot, we see that the mean energy of the emission along the line-scan arrow only has minor variation in the range of $6 \mathrm{meV}$, although it was usually observed to be slightly more red-shifted in the dark grains than in the bright grains in a plan-view electronbeam-induced current (EBIC) map [11]. The slight variation of the $C L$ map contrast means that there are many defects/impurities throughout the Si film because the optical activity of the Si film is dominated by deep band-tail states related to high defect/impurity levels [14].

To determine the minority carrier diffusion length in the poly-Si film, we developed an approach that is based on integrating-within one platform-conductive atomic force microscopy (C-AFM) and EBIC measurements inside an SEM (Fig. 4(a)). This particular setup has been shown 


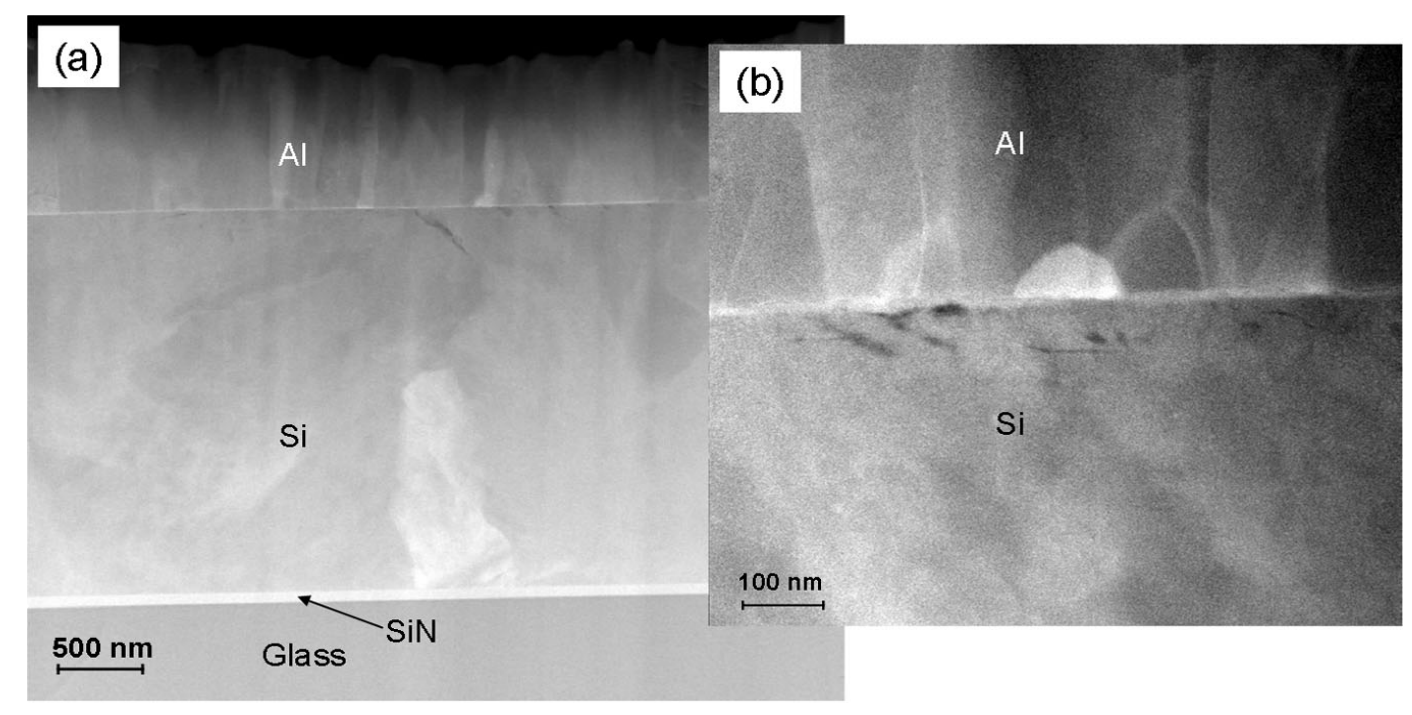

Fig. 5. (a) Z-contrast image at a lower magnification. (b) Z-contrast image at a higher magnification. Note that pinholes/microcracks/voids exist at the interface between the Al contact and the poly-Si.

to greatly improve the resolution of conventional EBIC measurements [15], which makes it especially suitable for measuring the diffusion length. In our setup, the ultrasharp metal tip (W), which forms a Schottky contact with the poly-Si, senses the current generated by the highly localized electron beam. The setup details have been shown elsewhere [16]. To actually conduct the measurement, we first acquired an AFM image with the AFM part operated in tapping mode. From the acquired AFM image (Fig. 4(b)), we specifically selected, for example, two regions 1 and 2 . At each region, the metal tip was fixed at a position and the electron beam was line scanned toward the tip. The EBIC line scans were carried out at $\mathrm{V}_{\mathrm{ac}}=15 \mathrm{kV}, \mathrm{I}_{\mathrm{b}}=0.5 \mathrm{nA}$, and $\mathrm{T}=300 \mathrm{~K}$. The current sensed by the metal tip was measured as a function of the distance between the electron beam and the metal tip (Fig. 4(c)). From the slope of each plot, we can derive the effective diffusion length $L_{p}$ of the minority carriers (in this case, holes) at that specific location. In most cases, the values of $L_{p}$ are about $2 \mu \mathrm{m}$. At some locations, $L_{p}$ is up to $10 \mu \mathrm{m}$ long. Note that the $L_{p}$ measured is the effective diffusion length, and its values are expected to be greatly improved if proper rear surface passivation is applied. It has been found that in p-type absorber layers the obtained diffusion lengths $L_{n}$ of minority carriers (electrons) could be up to $4 \mu \mathrm{m}$, as derived from the simulations performed with the 1-dimensional electronic device simulator PC1D [10]. Considering that the total thickness of EVA poly-Si layers is $\sim 2 \mu \mathrm{m}$, we conclude that the poly-Si film quality is good enough for effective carrier collection; the diffusion length is not a major limiting factor for EVA cells.

As pointed out previously [10], EVA solar cells are currently limited by two main factors (except for the opencircuit voltage $\mathrm{V}_{\mathrm{oc}}$ ): (1) the relatively high series resistance $R_{\mathrm{s}}\left(\geq 4 \Omega \mathrm{cm}^{2}\right)$, and (2) the relatively low short-circuit current density $\mathrm{J}_{\mathrm{sc}}\left(\leq 15.6 \mathrm{~mA} / \mathrm{cm}^{2}\right)$. To study the former, we did cross-sectional TEM. The cross-sectional specimen was prepared with a FIB workstation. The Z-contrast images are shown in Fig. 5 at different magnifications. It is evident that pinholes/microcracks/voids exist in the top layer of the poly-Si film. Some of these features can penetrate several hundred $\mathrm{nm}$ into the film. These features are detrimental to the device performance. In addition, the Al grains in the metal electrode are elongated along the film surface normal. At the current stage, it is unclear why the grains in the thermally evaporated Al contact are elongated. However, it seems that these grains do affect the conductivity of the electrode, because we observed that the resistivity of the contact is doubled compared to normal Al contacts. To increase $\mathrm{J}_{\mathrm{sc}}$, we tried to improve light trapping by applying a layer of white paint as a backsurface reflector [12]. Table 1 illustrates the improvement of the EQE and $\mathrm{J}_{\mathrm{sc}}$ of cells $2 \mathrm{~d}$ and $2 \mathrm{e}$ after white paint was applied. Also noted is the shift of the peak wavelength to longer wavelengths. Here illustrated is only one example in improving lighting trapping. There are several other ways we are currently investigating, namely, back-surface texturing, texturing of the glass superstrates, and an increase in cell thickness.

Table 1. EQE results of two solar cells before and after white paint was applied.

\begin{tabular}{c|c|c|c|c}
\multirow{2}{*}{ Cell } & \multicolumn{2}{|c|}{ Without white paint } & \multicolumn{2}{c}{ With white paint } \\
\cline { 2 - 5 } & $2 \mathrm{~d}$ & $2 \mathrm{e}$ & $2 \mathrm{~d}$ & $2 \mathrm{e}$ \\
\hline $\mathrm{J}_{\text {light }}\left(\mathrm{mA} / \mathrm{cm}^{2}\right)$ & 9.22 & 9.11 & 12.04 & 12.24 \\
\hline Peak EQE $(\%)$ & 51.9 & 51.5 & 56.4 & 56.6 \\
\hline $\begin{array}{c}\text { Peak } \\
\text { wavelength }(\mathrm{nm})\end{array}$ & 475 & 475 & 480 & 485 \\
\hline
\end{tabular}


To date, the best EVA cells produced on planar glass superstrates have achieved fill factors up to $64 \%$, series resistance values in the range of $4-5 \Omega \mathrm{cm}^{2}$, short-circuit current densities of up to $15.6 \mathrm{~mA} / \mathrm{cm}^{2}$, and efficiencies of $4.25 \%$. From the above discussions, we conclude that there is still much room for further improving device performance. With proper metallization schemes, good light trapping, and improved poly-Si film quality, we are confident that EVA cells will surpass the 10\%-efficiency mark.

\section{CONLUSIONS}

A wide range of characterization techniques were employed to carry out a systematic study of EVA silicon thin-film solar cells on glass. The SIMS depth profiles indicate the high level of impurity incorporation in the polySi films, especially $\mathrm{O}, \mathrm{C}, \mathrm{N}$, and Al. The $\mathrm{H}$ content is determined to be in the range of $10^{19}-10^{20} \mathrm{~cm}^{-3}$. From the $\mathrm{CL}$ map, the mean energy of the emission has only minor variations in the range of $6 \mathrm{meV}$, which indicates that the optical activity of the Si film is dominated by deep band-tail states related to high defect/impurity levels. Nevertheless, EBIC-based measurements indicate that the effective diffusion length $L_{p}$ of the minority carriers is about $2 \mu \mathrm{m}$ in most cases and can be up to $10 \mu \mathrm{m}$ in some regions. Thus, the diffusion length is presently not a major limiting factor for EVA cells. From Z-contrast images, we find pinholes/microcracks/voids at the top layer of the poly-Si film, and elongated Al grains. Finally, we demonstrate the improvement of the EQE and $\mathrm{J}_{\mathrm{sc}}$ of cells by applying white paint as a back-surface reflector to improve light trapping. From the results presented in this study, it is evident that much room remains for further improving device performance. We thus believe that $10 \%$ efficient EVA solar cells will be realized in the future.

\section{ACKNOWLEDGEMENTS}

F. Liu thanks Dr. Yanfa Yan at NREL for help with the FEI F20 TEM/STEM. O. Kunz and J. Wong acknowledge their Ph.D. scholarships from UNSW's Faculty of Engineering. The ARC Photovoltaics Centre of Excellence is supported by the Australian Research Council (ARC). At NREL, this work is supported by the U.S. Department of Energy under Contract No. DE-AC36-08-G028308.

\section{REFERENCES}

[1] R.E.I. Schropp, R. Carius, G. Beaucarne, MRS Bulletin 32, 2007, pp. 219-222.

[2] G. Beaucarne, Advances in OptoElectronics 2007, 2007, Article ID 36970.

[3] D.L. Staebler, C.R. Wronski, Appl. Phys. Lett. 31, 1977, pp. 292-294.

[4] M.A. Green, P.A. Basore, N. Chang, D. Clugston, R. Egan, R. Evans, D. Hogg, S. Jarnason, M. Keevers, P. Lasswell, J. O'Sullivan, U. Schubert, A. Turner, S.R. Wenham, T. Young, Solar Energy 77, 2004, pp. 857-863.

[5] M.L. Terry, A. Straub, D. Inns, D. Song, A.G. Aberle, Appl. Phys. Lett. 86, 2005, pp. 172108.

[6] P. I.Widenborg, A.G. Aberle, Advances in OptoElectronics 2007, 2007, Article ID 24584.

[7] P. Stradins, O. Kunz, D.L. Young, Y. Yan, K.M. Jones, Y. Xu, R.C. Reedy, H.M. Branz, A.G. Aberle, Q. Wang, Mater. Res. Soc. Symp. Proc. 989, 2007, pp. 0989-A1604.

[8] A.G. Aberle, J. Cryst. Growth 287, 2006, pp. 386-390.

[9] D. Song, D. Inns, A. Straub, M.L. Terry, P. Campbell, A.G. Aberle, Thin Solid Films 513, 2006, pp. 356-363.

[10] O. Kunz, Z. Ouyang, J. Wong, A.G. Aberle, Advances in OptoElectronics 2008, 2008, Article ID 532351.

[11] F. Liu, M.J. Romero, K.M. Jones, M.M. Al-Jassim, O. Kunz, J. Wong, A.G. Aberle, "Solid-phase crystallization of evaporated silicon thin films on glass for photovoltaics: $A$ combined SEM and TEM study", 2009 (submitted).

[12] O. Kunz, J. Wong, J. Janssens, J. Bauer, $O$. Breitenstein, A.G. Aberle, Prog. Photovolt: Res. Appl. 17, 2009, pp. 35-46.

[13] M.J. Keevers, A. Turner, U. Schubert, P.A. Basore, M.A. Green, "Remarkably effective hydrogenation of crystalline silicon on glass modules", 20th European Photovoltaic Solar Energy Conference, 2005, pp. 1305-1308.

[14] A.U. Savchouk, S. Ostapenko, G. Nowak, J. Lagowski, L. Jastrzebski, Appl. Phys. Lett. 67, 1995, pp. 82-84.

[15] M. Troyona, K. Smaali, Appl. Phys. Lett. 90, 2007, pp. 212110.

[16] M.J. Romero, F. Liu, C.-S. Jiang, M.M. Al-Jassim, O. Kunz, J. Wong, A.G. Aberle, "Imaging electron transport across grain boundaries in an integrated electron and atomic force microscopy platform: Application to polycrystalline-Si thin-film solar cells", 2009 (submitted). 